УДК 612.015.38

DOI: $10.18101 / 2306-1995-2019-2-3-9$

\title{
МЕТАБОЛИЧЕСКИЙ СИНДРОМ: ПАТОГЕНЕЗ, КРИТЕРИИ ДИАГНОСТИКИ И ЛЕЧЕНИЕ
}

\author{
(C) Архипова Эржена Владимировна \\ кандидат медицинских наук, старший преподаватель, \\ кафедра терапии, \\ Бурятский государственный университет им. Д. Банзарова \\ Россия, 670002, г. Улан-Удэ, ул. Октябрьская 36а \\ E-mail:arkhipova15@mail.ru
}

Метаболический синдром (МС) является одной из наиболее актуальных проблем в терапии и кардиологии, известно, что многие ассоциированные с МС состояния лежат в основе многих заболеваний сердечно-сосудистой системы, заболеваний печени, почек, сахарного диабета II типа. Метаболический синдром длительное время протекает без явной клинической симптоматики. Ранняя диагностика является наиболее актуальной задачей. В данной статье представлен современный взгляд на основные вопросы этиологии, патогенеза, клинических проявлений, а также современные подходы к коррекции метаболического синдрома с целью профилактики сердечно-сосудистой патологии, а также нарушений углеводного и липидного обменов.

Ключевые слова: метаболический синдром, сердечно-сосудистые заболевания, ожирение, профилактика сердечно-сосудистых заболеваний.

Для цитирования:

Архипова Э. В. Метаболический синдром: патогенез, критерии диагностики и лечение // Вестник Бурятского государственного университета. Медицина и фармация. 2019. Вып. 2. С. 3-9.

Метаболический синдром - это состояние, ассоциированное с высоким риском сердечно-сосудистых заболеваний. Со второй половины XX века и по настоящее время распространенность МС в популяции растет, принимая характер эпидемии. По данным ВО3 примерно 30\% жителей в мире страдают избыточным весом, из них 14,9\% - женщины, 16,8\% - мужчины [3].

MC наиболее распространен среди мужчин, a y женщин распространенность его возрастает в период менопаузы. Современный ритм жизни общества предрасполагает к тому, что МС «молодеет». Согласно Парижскому проспективному исследованию, которое длилось на протяжении 20 лет до 2004 г. У мужчин с МС имелся риск развития ишемической болезни сердца на 90\% выше, чем показатели в группе сравнения, а также увеличение риска возникновения внезапной смерти на $68 \%$ по сравнению с данными в контрольной группе. Также установлено, что наличие одного абдоминального ожирения сопровождается выраженным возрастанием риска, сопоставимое в целом с метаболическим синдромом [9]. По данным D. L. Sprecher и соавт., у пациентов с МС и ишемической болезнью сердца (ИБС) 
смертность от сердечно-сосудистых заболеваний увеличивается в 5 раз для женского пола и в 2 раза для мужского пола [18], а инфаркт миокарда и инсульт встречаются в 3,5 раза чаще [13]. В исследовании PAMELA 2005г. среди обследованных 3200 жителей г. Монза (Италия), составивших 64\% жителей, МС выявлен в 17,6\% у мужчин и в $16,8 \%$ у женщин. В Великобритании в исследованиях Goodenge Study и Ely Study распространенность среди мужчин составила $35 \%$ у мужчин моложе 55 лет, и 47\% у мужчин старше 55 лет. У женщин моложе 55 лет показатель заболеваемости был ниже и возрастал с возрастом [15].

По российским данным [3] частота встречаемости МС среди мужчин 40-55 лет составляет $44,4 \%$, у женщин в той же возрастной группе - 20,8\%. В исследовании Interheart, метаболический синдром выявляется у $26 \%$ среди взрослого населения. Достаточно высокая его распространенность среди пациентов, страдающих ожирением - 49\%; у пациентов с нарушенной толерантностью к глюкозе частота встречаемости МС составляет 50\%, а у пациентов с сахарным диабетом 80\% (6). Необходимо отметить, что распространенность МС среди детей и подростков за последние десятилетия выросла в 1,5 раза [12]. Таким образом, исследования проведенные в разное время в разных регионах планеты указывают на высокую распространенность МС среди популяции, что является актуальной социально-экономической проблемой, для решения которой чрезвычайно важным является ранняя диагностика и своевременное лечение основных составляющих МС.

Основными критериями МС являются:

- висцеральное ожирение, при котором окружность талии у женщин $\geq 80 \mathrm{~cm}$, у мужчин $\geq 94 \mathrm{~cm}$, в сочетании как минимум с двумя критериями:

- повышение триглицеридов (ТГ) $\geq 1,7$ ммоль/л, снижение уровня липопротеидов высокой плотности (ЛПВП) < 1,03 ммоль/л у мужчин, $<$ 1,29 ммоль/л у женщин;

- повышение АД > 130/85 мм рт.ст.;

- выявление нарушенной толерантности к глюкозе.

В российских рекомендациях принято учитывать содержание ЛПВП, ТГ, липопротеидов низкой плотности (ЛПНП), в то время как в зарубежных рекомендациях содержание ЛПНП не учитывается.

Среди факторов, влияющих на развитие $\mathrm{MC}$, выделяют генетическую предрасположенность, избыточное питание, синдром обструктивного апноэ сна, артериальную гипертонию, гиподинамию. В основе метаболического синдрома лежит первичная инсулинорезистентность и компенсаторная системная гиперинсулинемия. При диагностике инсулинорезистентности необходимо определение нескольких признаков: сахарного диабета II типа, нарушения толерантности к углеводам или проведение эугликемического 
гиперинсулинового клэмп-теста, при котором определяют влияние инфузии инсулина на метаболизм глюкозы.

По влиянию на уровень чувствительности тканей к инсулину наибольшее значение имеет гиподинамия и избыточное потребление жира [1]. Избыточное потребление насыщенных жирных кислот способствует изменению фосфолипидов в клеточных мембранах. Гипертриглицеридемия, повышение ЛПНП приводят к избыточному отложению липидов в мышцах и нарушению работы ферментов, участвующих в метаболизме глюкозы [19]. Как следствие в этой группе больных повышается риск развития инсулинорезистентности. Интенсивный липолиз в висцеральной жировой ткани приводит к выделению большого количества свободных жирных кислот. В свою очередь поступление свободных жирных кислот в гепатоциты способствует развитию стеатоза и стеатогепатита как проявления неалкогольной жировой болезни печени (НАЖБП). Возникший окислительный стресс приводит к увеличению продукции провоспалительных цитокинов, в частности фактора некроза опухоли $\alpha$ (ФНО $\alpha)[6]$. Также изучено, что избыточное содержание СЖК в крови служит источником накопления ТГ в мышцах, способствуя нарушению инсулинзависимой утилизации глюкозы в этих тканях [1]. Наряду с инсулинорезистентностью необходимо отметить лептинорезистентность. Лептин является ключевым медиатором между гипоталамо-гипофизарной системой и жировой тканью, он участвует в процессах регуляции веса тела. Гиперлептинемия при метаболическом синдроме тесно коррелирует с уровнем индекса массы тела (ИМТ), уровнем АГ, активностью АГ II, подтверждая патогенетическую взаимосвязь гиперлептинемии, активации нейрогуморальных систем и артериальной гипертонии у больных с ожирением [5].

Учитывая патогенетические механизмы развития МС, необходимо отметить важную роль эндотелиальной дисфункции (ЭД). Под термином «эндотелиальная дисфункция» определяется уменьшение способности эндотелиальных клеток продуцировать факторы, способствующие релаксации при сохраненном или увеличенном уровне продукции сосудосуживающих факторов, важным из которых является оксид азота. Дисфункция эндотелия сосудов является одним из ведущих звеньев в развитии атеросклероза [4]. Как отмечают исследователи, ранее акцентировавших внимание исключительно на ИР как основном патогенетическом факторе $\mathrm{MC}$, сейчас много внимания уделяется одному из факторов формирования МС - системного субклинического воспаления [17]. При системном воспалении всегда происходит взаимодействие эндотелия сосудов, форменных элементов крови, коагуляционной системы, системы комплемента. Компоненты МC могут провоцировать тромбообразование, что в свою очередь 
влечет за собой вероятность повышения риска сердечно-сосудистых осложнений $[1,15]$.

Принципы терапии МС

Успех терапии пациентов с МС зависит от выбора лекарственных препаратов, которые должны оказывать влияние на ключевые патогенетические изменения, такие как абдоминальное ожирение, изменения углеводного и липидного обменов. К немедикаментозным методам лечения относят физическую нагрузку, диету и отказ от курения. Показано, что соблюдение физически активного режима жизни и коррекция диеты способствуют снижению риска развития сердечно-сосудистых заболеваний на $50 \%$ по сравнению с гиподинамией [8]. Более того увеличение расхода энергии на 1000 ккал в неделю ассоциировано с уменьшением смертности на 20\% [8]. У многих людей мероприятия по модификации образа жизни не могут полностью корригировать имеющиеся нарушения, а выраженность факторов риска с годами увеличивается, вследствие этого и возрастает потребность в медикаментозной терапии.

В настоящее время не существует препаратов, которые могут значимо снижать все метаболические факторы риска в течение длительного времени. Вследствие этого медикаментозное лечение включает коррекцию каждого конкретного фактора риска в отдельности, например, комбинацию гиполипидемических препаратов, антигипертензивных препаратов и сахароснижающей терапии.

В первую очередь по влиянию на углеводный обмен показаны препараты группы бигуанидов, представителем которых является метформин. Метформин не влияет на секрецию инсулина, в основном он способствует повышению чувствительности тканей к инсулину, снижает гиперинсулинемию, способствует снижению массы тела, АД и улучшению функции сосудистого эндотелия у больных с ожирением и АГ [3]. При этом метформин является препаратом первой линии при лечении неалкогольного стеатогепатита с учетом доказательной базы, снижая уровень свободных жирных кислот в крови и уменьшая их токсическое влияние на гепатоциты [2]. Также, является патогенетически обоснованным назначение урсодезоксихолевой кислоты (УДХК) при лечении неалкогольного стеатогепатита. Данный препарат имеет плейотропное действие, обладая иммуномодулирующим, гипохолестеринемическим, цитопротективным, литолитическим действием. Показано, что применение УДХК в течение как минимум 6 мес. приводит к уменьшению выраженности стеатоза и воспаления по данным гистологического исследования печени [6]. Особенно актуально назначение УДХК пациентам, которым показаны статины в качестве гиполипидемической терапии, но при этом у них сохраняется высокий уровень трансаминаз печени в связи с неалкогольным стеатогепатитом. 
При лечении артериальной гипертонии необходимо применение препаратов не только обладающих антигипертензивной активностью, но и влияющих на метаболический профиль. Эффективность агонистов I1-имидазолиновых рецепторов моксонидина продемонстрирована в ряде исследований [11]. В исследовании Н. А. Коломейченко и соавт. [5] показано статистически достоверное снижение степени инсулинорезистентности на фоне лечения моксонидином. Антигипертензивная эффективность агониста I1-имидазолиновых рецепторов моксонидина при использовании его при метаболическом синдроме ассоциируется с корригирующим влиянием в отношении инсулино- и лептинорезистентности.

Лечение ожирения является не менее сложной задачей, чем лечение любого другого хронического заболевания. Приверженность пациентов к рекомендациям по снижению массы тела низкая из-за необходимости постоянного контроля аппетита. Здесь необходим комплексный подход, включающий применения низкокалорийной диеты и увеличения физической активности. Рекомендовано употреблять в сутки около 30 г пищевых волокон, что соответствует 400 г овощей и фруктов [14]. Псиллиум - производное шелухи оболочек семян подорожника овального относится к высоковязким, гельобразующим неферментированным пищевым волокнам. В России помимо биологически активных добавок, представлен лекарственный препарат Мукофальк. Растворимые пищевые волокна связывают воду (1 г связывает 40 мл воды) и на уровне желудка выступают как наполнитель, способствуя снижению аппетита, на уровне тонкого и толстого кишечника выполняют роль адсорбента холестерина, желчных кислот, сахара, протеолитических бактерий и эндотоксинов. В исследовании Sola R. et al (2007) продемонстрировано дополнительное влияние псиллиума на состояние сердечно-сосудистой системы. У пациентов с ИБС псиллиум приводил к уменьшению уровня ТГ и увеличению холестерина ЛПВП. Таким образом, назначение псиллиума патогенетически обосновано для коррекции основных проявлений метаболического синдрома.

В заключении необходимо отметить, что раннее выявление предикторов метаболического синдрома имеет выраженное клиническое значение с точки зрения профилактики развития сахарного диабета II типа, сердечно-сосудистых заболеваний, вносящих существенный вклад в структуру смертности среди населения.

Лuтература

1. Бутрова С. А. Современные возможности и перспективы терапии метаболического синдрома // Трудный пациент. 2007. № 6-7. С. 31-34.

2. Ивашкин В. Т., Лапина Т. Л. Гастроэнтеррология. Национальное руководство. Краткое издание. М.: Гэотар-Медиа, 2014. 480 с.

3. Диагностика и лечение метаболического синдрома. 
4. Калашникова М. Ф. Метаболический синдром: современный взгляд на концепцию, методы профилактики и лечения // Эффективная фармакотерапия. Эндокринология. 2013. № 6(55). С. 52-63.

5. Коррекция лептинорезистентности - новая терапевтическая стратегия при метаболическом синдроме / Н. А. Коломейченко [и др.] Кремлевская медицина. Клинический вестник. 2009. №2. С.129-133.

6. Неалкогольная жировая болезнь печени как проявление метаболического синдрома / О. Н. Корнеева [и др.] // Консилиум. Гастроэнтерология. 2015. № 9(139). С. 20.

7. Метаболический синдром: история развития, основные критерии диагностики / Ю. Н. Беленков [и др.] // Рациональная фармакотерапия в кардиологии, 2018. № 14(5). С. 757-764.

8. Метаболический синдром / под ред. Г. Е. Ройтберг. М.: Пресс-информ, 2007. $224 \mathrm{c}$.

9. Шляхто Е. В., Конради А. О. Эпидемиология метаболического синдрома в различных регионах. Зависимость от используемых критериев и прогностическое значение // Артериальная гипертензия. 2007. № 2. Т. 13. C. $95-112$.

10. Diagnosis and treatment of metabolic syndrome, Russian recommendations. 2nd revision (2009). URL: http://www.scardio.ru/content/ images/recommendation/ nacionalnye_rekomendacii_po_diagnostike_i_lecheniyu _metabolicheskogo_sindroma.pdf. (In Russ.) [cited by Sep 25, 2019].

11. De Luca N., Izzo R., Fontana D., et al. Haemodynamic and metabolic effects of rilmenidine in hypertensive patients with metabolic syndrome X. A doubleblind parallel study versus amlodipine. J Hypertens 2000. 18:1515. P. 22.

12. Douketis J. D., Sharma A. M. Obesity and cardiovascular disease: pathogenic mechanisms and potential benefits of weight reduction. Semin Vasc Med. 2005. № 5(1). P. 25-33.

13. Isomaa B., Almgren P., Tuomi T. et al. Cardiovascular morbidity and mortality associated with the metabolic syndrome // Diabetes Care. 2001. Vol. 24. № 4. P. 683-689.

14. Lambeau K. V., McRorie J. W. Fiber supplements and clinically proven health benefits: How to recognize and recommend an effective fiber therapy. Review systematic. J Am Assoc Nurse Pract. 2017. 29:216-23.

15. Mohamed-Ali V., Gould M. M., Gillies S., Goubet S., Yudkin J. S., Haines A. P. Association of proinsulin - like molecules with lipids and fibrinogen in non-diabetic subjects-evidence against a modulating role for insulin. Diabetologia, 2005. 38. P. 1110-1116.

16. Resnick H. E., Hones K., Ruotolo G., et al. Insulin resistance, the metabolic syndrome, and risk of incident cardiovascular disease in nondiabetic American Indians: the Strong Heart Study. Diabetes Care. 2003. № 26. P. 861-867.

17. Seyidova G. B. C-reactive protein and its connection with the metabolic syndrome associated with ischemic disease and the metabolic syndrome of pre-and postmenopausal people. Bulletin of Arrhythmology. 2005. № 14. P. 47-50.

18. Sprecher D. L., Pearce G. L. How deadly is the "deadly quartet"? A postCABG evaluation // J. Am. Coll. Cardiol. 2000. Vol. 36. № 4. P. 1159-1165. 
19. Sung K. C., Reaven G. Fasting plasma triglyceride concentration: A possible approach to identify increased risk of statin-induced type 2 diabetes. Diab Vasc Dis Res. 2015. 12(5). P. 373-376.

\section{METABOLIC SYNDROME:}

PATHOGENESIS, DIAGNOSTIC CRITERIA AND TREATMENT

\section{Erzhena V. Arkhipova}

Candidate of Medical Sciences

Senior Lecturer

Dorzhi Banzarov Buryat State University

36a Oktyabrskaya st, Ulan-Ude, 670002, Russia

E-mail: arkhipova15@mail.ru

The one of the pressing issues in therapy and cardiology is metabolic syndrome. This syndrome is associates with heart diseases, liver and kidneys diseases, diabetes and many others. The metabolic syndrome proceeds for a long time without clinical manifestations. So early diagnosis of syndrome is one of the main problems. The modern view of the etiology, the pathogenesis, the clinical manifestations are presented in this article. There are presented correction methods in the treatment of metabolic syndrome.

Keywords: metabolic syndrome, heart diseases, obesity, prevention of heart diseases. 